\title{
CORRESPONDENCE
}

From A. Kim Burton, DO, MRO, Research Officer, The Osteopathic Association of Great Britain, 30 Queen Street, Huddersfield HD1 2SP, W. Yorks.

To the Editor:

Dear Sir,

\section{BACK PAIN IN GRAND PRIX DRIVERS}

It is likely that most practitioners involved in the treatment of sports injuries will, from time to time, be consulted by motor racing drivers. The satisfactory management of their problems, as with all sports injuries, requires an understanding of the potential aetiological forces inherent in the sport.

During $1981 / 2$ there was considerable reference, in the motor sport press, to the back pain being suffered by the Formula One Grand Prix drivers, which coincided with an increase in aerodynamic down force and reduction in suspension movement. The design concepts involved are also being applied to the lesser formulae, both professional and amateur. There has been recent reference in the biomechanics literature to the possible relationship between back pain and unattenuated skeletal shock waves, and should there be a causal link between stiffer suspension and back pain it is likely that these other racing drivers will also suffer increased back pain.

\section{Field Study}

A verbal questionnaire concerning back pain related to driving was administered to eight of the 32 regular Grand Prix drivers in June 1982 and an examination made of their race car seats. At the same time a similar questionnaire was administered to 24 non-racing drivers.

The results of the questionnaires revealed that $88 \%$ of the Grand Prix drivers were regularly experiencing low back pain both during and following driving their race cars, whilst $63 \%$ complained of driving-related cervical symptoms. None were without spinal symptoms. Of the non-racing drivers $25 \%$ had driving related lumbar symptoms, $13 \%$ had cervical symptoms and $62 \%$ had no symptoms. The difference between these samples was statistically significant.

Examination of the racing seats showed that the drivers were well located laterally, were firmly held by their seat belts, sat with a backrest angle averaging $118^{\circ}$ and had their knees and elbows somewhat flexed. The seats were constructed from fibre-glass and had no inbuilt padding or lumbar support, but half the drivers had added some foam padding.

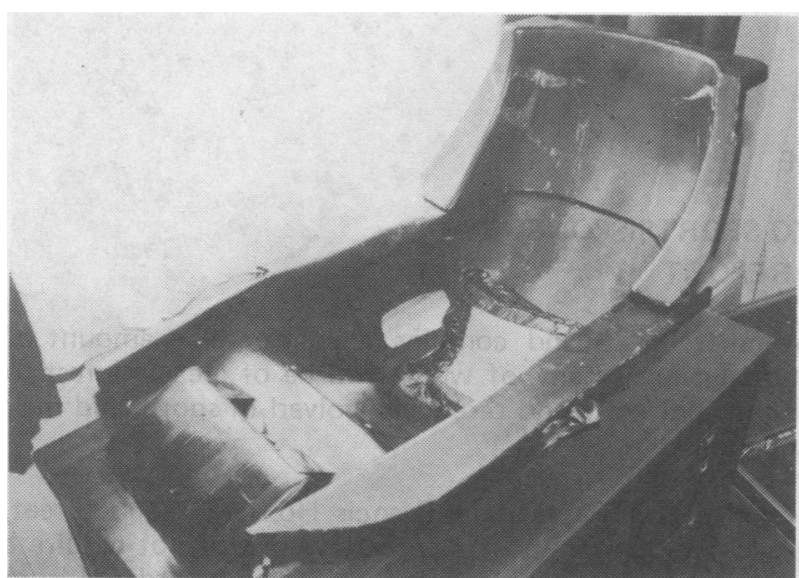

Fig. 1: A typical F1 fibre-glass seat - showing lateral and knee support, lack of lordosis and driver-added padding.

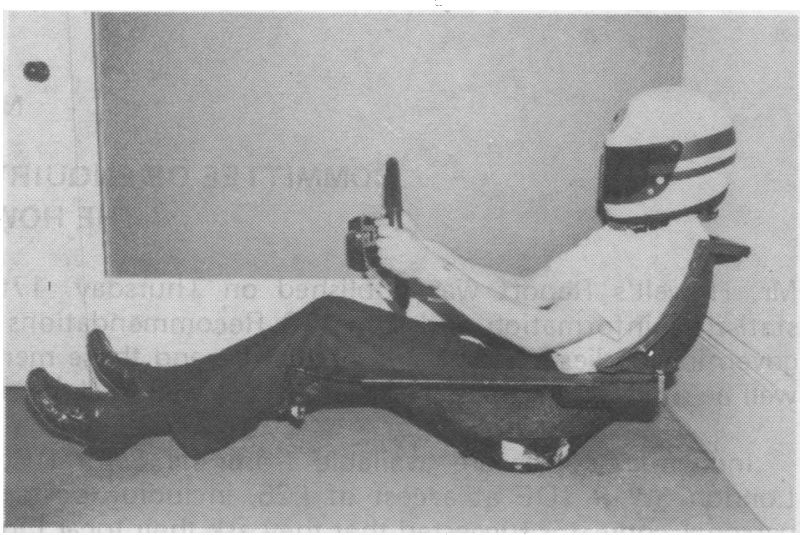

Fig. 2: A driver in-situ in the seat - showing angles of backrest, neck, arms and legs. 


\section{Discussion}

The Grand Prix racing drivers studied showed a significantly increased incidence of spinal symptoms related to their driving activities, when compared with ordinary road drivers, despite the fact that they are located in well fitting seats in what is generally considered to be a low-stress posture. Their symptoms were apparently the same whether racing or testing, the latter being times of low psychological stress. All of the drivers sampled related their symptoms to the jarring produced by the lack of suspension movement inherent in the design of the cars and furthermore stated that their symptoms had increased since the advent of high levels of aerodynamic down-force. Though their cervical symptoms may be contributed to by the lateral forces in cornering, this is unlikely to be the case with lumbar symptoms. Pedal pressures and steering forces were not considered contributory factors.

It seems possible that the increased levels of spinal symptoms in these drivers could arise from the input of unattenuated vertical compression forces to their spines. If this is the case then some concern is justified for the long-term spinal health of these competitors and also for that of others participating in sports which may involve repetitive spinal shock waves such as motorcycle and powerboat racing, water skiing, downhill skiing and the like.

Further work is in progress to relate the spinal symptoms in Grand Prix drivers to the changing characteristics of the cars, measured by accelerometers attached to the seats, and these findings will be reported in due course.

\section{Conclusion}

If it can be demonstrated that there is, indeed, a causal link between spinal shock waves and back pain in Grand Prix drivers, and others in similar sports, then the management of these patients should include devices designed to attenuate the forces concerned. The potential role of energy absorbent seat pads, made of visco-elastic polymer perhaps, should be investigated.

Yours faithfully,

\section{A. K. BURTON}

\section{BOOK REVIEW}

\section{Title: $\quad$ TRAINING AND CONDITIONING OF ATHLETES}

Authors: $\quad$ Max M. Novich, MD and Buddy Taylor, MS, ATC

Publishers: $\quad$ Lea and Febiger, Philadelphia, USA ISBN 0-8121-0833-7

$$
\text { Price Glossy cover. } 320 \text { pages. }
$$

Although very much American orientated, there is a mass of information in this book which will be of use to those coaches and Chartered Physiotherapists who are entering the field of sport. Whilst making some philosophical observations it strongly emphasises the ethical and legal implications of those who become involved with the training and conditioning of athletes in all age groups and whilst perhaps lightly scanning some aspects of sport and its associated medical aspects attention is drawn to a wide variety of factors.

Some of the techniques described may not be familiar in the United Kingdom and without clinical trials it would be difficult to comment on their efficacy but clearly the authors' offer their own information with confidence. Published c.v.'s indicate that Dr. Novich is widely sxperienced in sport from Olympic to school teams whilst Mr. Taylor has handled more Olympic Gold Medal Winners than any other trainer in the United States.

The book has a good index and a very useful glossary. It is illustrated with a mixture cf line drawings and photographs, some of which are re-printed with full credit to the original publication.

It would be an advantage to the student to have this book available. 